\title{
Influence of the Initial State of Samples From Steel 20 on the Structural-Phase Condition to the Stable Zone Localization of Macrodeformation
}

\author{
Nikolai Ababkov ${ }^{1 *}$, Alexander Smirnov ${ }^{1}$, Vladimir Danilov ${ }^{2}$, Natalia Popova $^{3}$, Elena \\ Nikonenko ${ }^{3}$ and Nina Koneva ${ }^{3}$ \\ ${ }^{1}$ T.F. Gorbachev Kuzbass State Technical University, Department of Mechanical Engineering, \\ 650000 Kemerovo, 28 Vesennya st., the Russian Federation \\ ${ }^{2}$ Institute of Strength Physics and Materials Science SB RAS, Laboratory of Strength Physics, \\ 634055, Tomsk, 2/4 Akademicheskiy pr., the Russian Federation \\ 3 Tomsk State University of Architecture and Civil Engineering, Department of Physics, 634003 \\ Tomsk, 2 Solyanaya Sq., the Russian Federation
}

\begin{abstract}
One of the most important tasks of technical diagnostics and examination of industrial safety is the problem of assessing the residual life of long-running technical devices of hazardous production facilities. The paper presents the results of the study of the structural-phase state in a stable zone of localization of macrostrains, depending on the initial state of samples from steel 20. The samples were investigated without exploitation, after operation without destruction and with destruction. The samples were stretched at the same speed until a stable zone of strain localization appeared, after which the loading was stopped. The connection is established between the processes of localization of macrostrains and the evolution of the substructural state for steel 20. It has been established that the mechanism of localization of macrodeformations is the achievement of critical values of a fragmented substructure, in other words, according to the theory of evolution of substructural transformations, a bifurcation point occurs when the $\%$ fragmented substructure prevails. The critical values of dislocation density are established, which lead to a change in the type of dislocation substructure for equipment made of steel 20 .
\end{abstract}

\section{Introduction}

In the process of operation of the elements of the technical devices of hazardous production facilities (TDHPF) of the thermal power industry there are a number of problems that can lead to man-made disasters and human victims.

For such elements of the thermal power industry, such as water pipes, which are made of steel 20, the process of separating structurally free graphite [1] in the metal of welded joints and in the base metal is characteristic. Most often this phenomenon occurs on the

${ }^{*}$ Corresponding author: E-mail: n.ababkov@rambler.ru 
sections of pipes with the highest stresses, namely in the metal of the bends of the water inlet pipes. When fulfilling the requirements of regulatory documentation $[2,3]$ due to the presence of graphite in the base metal of the pipe, it is often necessary to encounter overhaul of all welded joints of the steam line or replacement of the entire steam line. This problem is currently highly relevant and applies to medium pressure steam pipelines. Despite the exceptional danger of objectively acting factors occurring in the metal of these steam pipelines, the mandatory work on their diagnosis is not always carried out in the required amounts [1].

One of the most important tasks of technical diagnostics and examination of industrial safety is the problem of assessing the residual life of long-running technical devices of hazardous production facilities. Currently, for these purposes, integrated approaches are used, including cumbersome calculation algorithms, analysis of non-destructive and destructive testing results, as well as metallography. Thus, resource assessment is a timeconsuming process, not always ensuring the required accuracy of the results obtained due to the summation of various kinds of errors (calculations, equipment, human factor). A number of approaches to assessing the critical state of long-term equipment use information on the characteristics of the metal after failure [4-6]. While information about the patterns of localization of plastic flow in a loaded material [7], which occurs before the formation of a neck and accurately indicates the place of future destruction, can serve as a more perfect critical indicator for stopping equipment operation. For these purposes, it is necessary to have data on the nature of the localization of the deformation and the structural and phase state in the materials of the heat and power equipment both in the initial state and after operation for a long time.

The purpose of the study was to determine the parameters of the structural-phase state and the internal stress fields of deformed tensile steel 20. All studies were performed in localized deformation zones of three steel states of a 20: 1 sample of the initial state, 2) an unbroken sample, and 3) a broken sample.

\section{Materials and research methods}

The object of the study was steel 20 . The chemical composition of the studied steel is given in table 1 .

Table 1. Chemical composition, steel 20

\begin{tabular}{|c|c|c|c|c|c|c|c|c|c|}
\hline \multicolumn{10}{|c|}{ Mass fraction of elements,\% } \\
\hline $\mathrm{C}$ & $\mathrm{Si}$ & $\mathrm{Mn}$ & $\mathrm{Cr}$ & $\mathrm{Ni}$ & $\mathrm{Cu}$ & $\mathrm{S}$ & $\mathrm{P}$ & $\mathrm{As}$ & $\mathrm{Fe}$ \\
\hline $\begin{array}{c}0.17- \\
0.24\end{array}$ & $0.17-0.37$ & $0.35-0.65$ & till 0.25 & till 0.25 & till 0.25 & till 0.04 & till 0.035 & till 0.08 & $\sim 98$ \\
\hline
\end{tabular}

Mechanical uniaxial tensile tests were performed with a constant speed on a Walter + Bai AG LFM-125 testing machine with simultaneous registration of strain localization patterns using digital image correlation (DIC) [8,9]. Samples without exploitation, after exploitation without destruction and with destruction were investigated. The samples were stretched at the same rate of $0.8 \mathrm{~mm} / \mathrm{min}$ until a stable zone of strain localization appeared, after which the loading was stopped. 


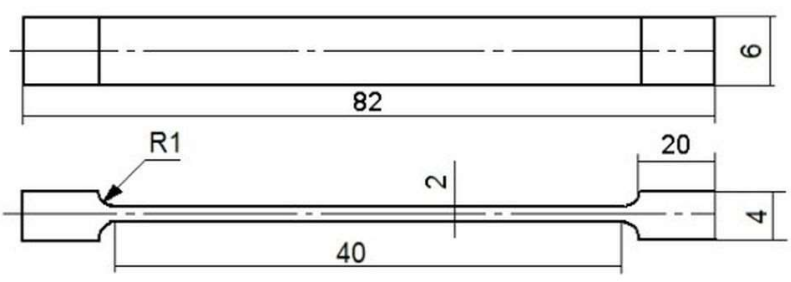

Fig. 1. The shape and size of samples for experimental studies.

The method of investigating the zones of localized deformation was the method of transmission electron diffraction microscopy (TEM) on thin foils using an EM-125 electron microscope at an accelerating voltage of $125 \mathrm{kV}$ [5]. The working magnification in the microscope column was 25,000 times.

As a result of the conducted studies, the phase composition was determined for each sample (qualitatively and quantitatively), and the following fine structure parameters were calculated: volume fractions of structural components of steel, scalar $\rho$ and excess $\rho_{ \pm}$ dislocation density, crystal lattice torsion $\chi$, internal stress amplitude (shear stress and longrange stress). All quantitative parameters of the fine structure are determined both in each structural component of the steel and in general for each sample [10-12].

At the qualitative and quantitative level, particular attention was paid, firstly, to the redistribution of carbon atoms in all studied states of steel, namely, the locations of the concentration of carbon atoms (solid solution, particles of the carbide phase, lattice defects) were determined [13-15].

\section{Research results and discussion}

In the initial state, the matrix of steel 20 is a $\alpha$-phase - a solid solution of carbon and alloying elements (see Table 1) in $\alpha-\mathrm{Fe}$ with a bcc crystal lattice. The morphological components of the $\alpha$-phase are lamellar perlite and ferrite. The volume fraction of plate perlite is $85 \%$, ferrite $-15 \%$. Typical images of the ferritic-pearlitic structure are shown in fig. 2 

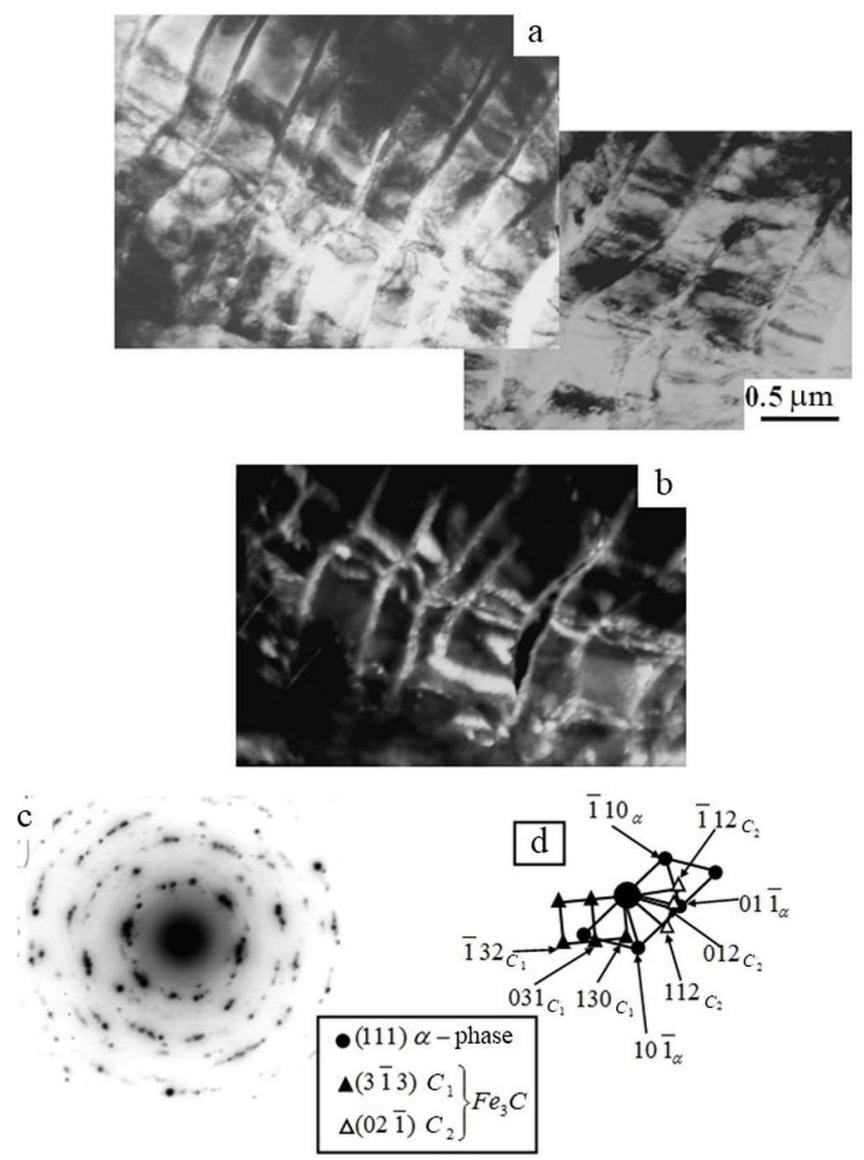

Fig. 2. Electron-microscopic image of unfragmented lamellar perlite in the zone of localized deformation of the original steel sample 20: $a$ - bright-field image; $b$ - dark-field image obtained in closely located $[01 \overline{1}] \alpha$-phase and cementite[012] reflexes; $c-$ microdiffraction pattern and $d-$ its indexed scheme.

Studies have shown that, as in the sample of the initial state of steel 20, the metal matrix of the sample after operation, but without destruction, is the $\alpha$-phase - solid solution of carbon and alloying elements in-Fe with a bcc crystal lattice. In addition, morphological components of the $\alpha$-phase are lamellar perlite and ferrite. The volume fraction of plate perlite, as in the original sample, is $85 \%$, ferrite $-15 \%$. Typical images of the ferritepearlite structure are shown in fig. 3. It can be seen from the presented figure that, as in the initial state, in the zone of localized deformation of the unbroken sample, plate perlite is present in the form of unfragmented (also 25\%) and fragmented (also 60\%). Ferrite is also present as unfragmented $(5 \%)$ and partially fragmented $(10 \%)$. The average size of the fragments in pearlite decreased somewhat and was equal to $0.7 \mu \mathrm{m}$, in the ferrite it remained the same, i.e. $0.5 \mu \mathrm{m}$. 


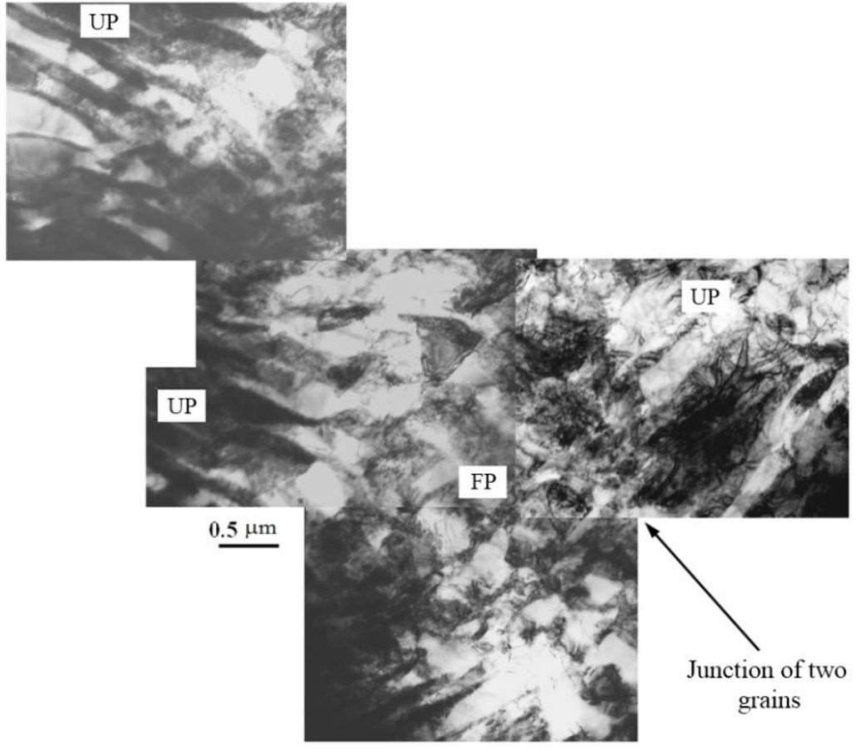

Fig. 3. Electron-microscopic image of the structure of lamellar pearlite in the zone of localized deformation of the unbroken sample of steel 20 (UP - unfragmented, FP - fragmented perlite)

The matrix of the metal of the sample after operation and after fracture, as in samples of steel 20 of the initial state and in the non-destructed state, represents the $\alpha$-phase - solid solution of carbon and alloying elements in $\alpha-\mathrm{Fe}$ with a bcc crystal lattice. Also morphological components of the $\alpha$-phase are lamellar perlite and ferrite. The volume fraction of plate perlite is $85 \%$, ferrite $-15 \%$.

Lamellar perlite is also present in the unfragmented (Fig. 4) and fragmented forms. Unfragmented perlite plate is often defective and even partially destroyed. The destroyed plates of cementite in the original and not destroyed samples were not detected. This is the first difference in the structure of the destroyed sample. The volume fraction of unfragmented lamellar perlite, as before, is $25 \%$ of the volume of the material.

Thus, in the destroyed sample in the zone of localized deformation, fragmented lamellar perlite is represented as a set of the following structures: 1) dislocation fragments $(45 \%)$ with an average size of $0.4 \mu \mathrm{m}$, inside of which rounded cementite particles are present on the dislocations; lamellar particles of cementite; 2) microcrystalline structure $(10 \%)-$ micrograins (or dislocation-free fragments) surrounded by cementite interlayers and having an average size of $\sim 0.2 \mu \mathrm{m}$, and 3 ) nanocrystalline structure (5\%) with a dislocation-free grain size (fragments) of $55 \mathrm{~nm}$, in the joints which there are particles of cementite. 


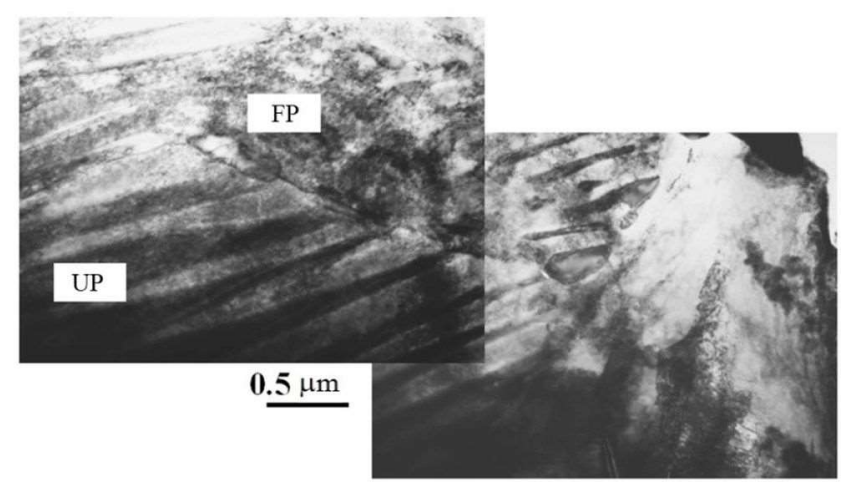

Fig. 4. Electron-microscopic image of the structure of lamellar perlite in the zone of localized deformation of the destroyed steel sample 20 (UP - unfragmented, FP - fragmented perlite)

It must be emphasized that, unlike the initial and not destroyed samples, all grains of ferrite are partially fragmented in a destroyed sample.

The method of transmission electron microscopy showed that both perlite and ferrite are characterized by the presence of a dense dislocation structure. Dislocations uniformly fill the crystals, forming a sharply twisted and tangled lines like a three-dimensional grid. It is well visible on presented on fig. 5 micrographs. The values of the mean scalar dislocation density $(\rho)$ in each morphological component of the structure, as well as in the material as a whole, for the studied samples are given in Table. 2

Table 2. The magnitude of the scalar density of dislocations in various morphological components of the fine structure and in the whole material $\left(\rho \times 10^{-10} \mathrm{~cm}^{-2}\right)$

\begin{tabular}{|c|c|c|c|c|c|c|c|}
\hline \multirow[b]{2}{*}{ Sample status } & \multirow[b]{2}{*}{$\begin{array}{l}\text { Unfragmented } \\
\text { perlite }\end{array}$} & \multicolumn{3}{|c|}{ Fragmented perlite } & \multirow[b]{2}{*}{$\begin{array}{l}\text { Unfragmented } \\
\text { ferrite }\end{array}$} & \multirow[b]{2}{*}{$\begin{array}{l}\text { Partially } \\
\text { fragmented } \\
\text { ferrite }\end{array}$} & \multirow{2}{*}{$\begin{array}{c}\text { In } \\
\text { genera } \\
1 \text {, the } \\
\text { materi } \\
\text { al }\end{array}$} \\
\hline & & $\begin{array}{l}\text { Dislocation } \\
\text { fragments }\end{array}$ & $\begin{array}{l}\text { Micro- } \\
\text { grain }\end{array}$ & $\begin{array}{l}\text { Nano- } \\
\text { grain }\end{array}$ & & & \\
\hline Initial & 2.50 & 2.65 & - & - & 2.72 & 2.45 & 2.60 \\
\hline An unbroken & 2.28 & 2.20 & - & - & 2.50 & 2.25 & 2.24 \\
\hline A broken & 1.88 & 1.91 & 0.91 & 0 & - & 1.93 & 1.90 \\
\hline
\end{tabular}

It follows from the table that when considering the change in $\rho$ in the zone of localized deformation in the samples in the direction of "initial" $\rightarrow$ "not destroyed" $\rightarrow$ "destroyed" in all morphological components of the structure, as well as in general, for each sample there is a decrease in, although insignificant. In addition, in unfragmented perlite, the value of it is always slightly less than in fragmented perlite, and in ferrite the opposite.

The rather high scalar dislocation density formed in all the morphological components of all the samples creates internal stresses in the material $-\sigma_{L}$ shear stresses. From Table 3 it can be seen that the value of the amplitude of $\sigma_{\mathrm{L}}$ in all samples is rather close, but, nevertheless, in the initial sample in all morphological components of the structure has the greatest value of $\sigma_{\mathrm{L}}$. 

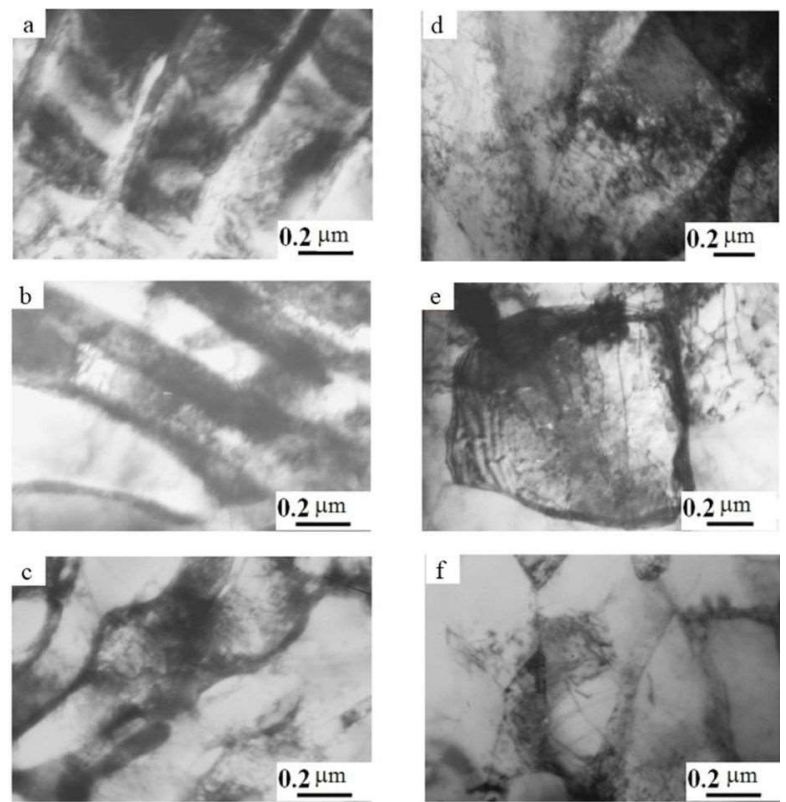

Fig. 5. The dislocation structure in the zone of localized deformation in various steel samples 20 in unfragmented $(\mathrm{a}-\mathrm{c})$ and fragmented $(\mathrm{d}-\mathrm{f})$ lamellar pearlite: $\mathrm{a}, \mathrm{d}$ - initial; b, e - undestroyed; c, f destroyed. Electron microscopic images

Table 3. Amplitude of shear stresses $\sigma_{\mathrm{L}}$ in various morphological components of the fine structure and in the whole material (MPa)

\begin{tabular}{|c|c|c|c|c|c|c|c|}
\hline \multirow[b]{2}{*}{$\begin{array}{l}\text { Sample } \\
\text { status }\end{array}$} & \multirow[b]{2}{*}{$\begin{array}{l}\text { Unfragmented } \\
\text { perlite }\end{array}$} & \multicolumn{3}{|c|}{ Fragmented perlite } & \multirow[b]{2}{*}{$\begin{array}{c}\text { Unfragmente } \\
\text { d ferrite }\end{array}$} & \multirow[b]{2}{*}{$\begin{array}{l}\text { Partially } \\
\text { fragmented } \\
\text { ferrite }\end{array}$} & \multirow{2}{*}{$\begin{array}{c}\text { In } \\
\text { general } \\
\text {, the } \\
\text { materia } \\
1\end{array}$} \\
\hline & & $\begin{array}{l}\text { Dislocatio } \\
n \\
\text { fragments }\end{array}$ & $\begin{array}{c}\text { Micro- } \\
\text { grain }\end{array}$ & $\begin{array}{l}\text { Nano- } \\
\text { grain }\end{array}$ & & & \\
\hline Initial & 315 & 325 & - & - & 330 & 315 & 320 \\
\hline $\begin{array}{c}\text { Undestroye } \\
\mathrm{d}\end{array}$ & 300 & 295 & - & - & 315 & 300 & 295 \\
\hline Destroyed & 275 & 275 & 190 & 0 & - & 275 & 250 \\
\hline
\end{tabular}

\section{Conclusions}

1. Studies of the structural and phase state of the metal of the samples without exploitation, after exploitation without fracture and with the destruction of steel 20 in the stable zone of localization of macrostrains were performed. The connection is established between the processes of localization of macrostrains and the evolution of the substructural state for steel 20 .

2. It has been established that the mechanism of localization of macrodeformations is the achievement of critical values of a fragmented substructure, in other words, according to the theory of evolution of substructural transformations, a bifurcation point occurs when the $\%$ fragmented substructure prevails. The critical values of dislocation density are established, which lead to a change in the type of dislocation substructure for equipment made of steel 20.

\section{References}

1.M. Shklyarov, V. Osmakov, G. EdachevTherm. Eng. 5, 360 (1999) 
2. K. Grote, E. Antonsson Handbook of Mechanical engineering (Springer, New York, 2008)

3. F. Kreith The CRC handbook of thermal engineering (CRC Press, Boca raton, 2000)

4. V. M. Segal, N. I. Noskova, R. R. Mulyukov et al. Severe plastic deformation: toward bulk production of nanostructured materials (Nova Science Publishers, Inc., New York, 2006)

5. A. N. Smirnov, N. V. Ababkov IOP Conf. Ser.: Mat. Sc. and Eng. 91, 012005 (2015)

6. A. Smirnov, A. Logov, N. Ababkov AIP Conf. Proc. 1698, 020009 (2016)

7. L. B. Zuev Journal of Applied Mechanics and Technical Physics. 58:2, 328 (2017)

8. V. I. Danilov, V. V. Gorbatenko, D. V. Orlova, L. V. Danilova, A. N. Smirnov Steel in Translation.48:2, 87 (2018)

9. V. I. Danilov, D. V. Orlova, L. B. Zuev, Materials and Design. 32, 1554 (2011)

10. F. Campbell Elements of Metallurgy and Engineering Alloys (ASM International, Ohio, 2008)

11. F. Brent, H. James Transmission Electron Microscopy and Diffractometry of Materials (Springer, New York, 2013)

12. G.Vorob'ev, V.PopovaSoviet Physics Journal 8:3, 29 (1965)

13. V. E.Gromov, K. V. Morozov, K. V. Alsaraeva, A. B. Yur'ev, Y. F. Ivanov Steel in Translation. 44:12, 883 (2014)

14. E. V. Kozlov, N. A. Popova, L. N. Ignatenko, L. A. Teplyakova, A. A. Klopotov, N. A. Koneva Russian Physics Journal. 45:3, 285 (2002)

15. E. V. Kozlov, N. A. Popova, E. E. Pekarskaya, N. A. Koneva, A. N. Zhdanov, Materials Science and Engineering 1:2, 789 (2004) 